\title{
25 jaar moord in Nederland
}

\section{Een trendanalyse van geslacht en leeftijd van slachtoffers van moord}

\author{
Pauline Aarten, Hanneke Schönberger \& Marieke Liem
}

Deze studie beschrijft de trend in slachtofferschap van moord in Nederland in de periode 1992-2016. Hierbij is gebruik gemaakt van de Dutch Homicide Monitor. De bevindingen laten zien dat het moordcijfer sinds de jaren negentig aan het dalen is. Deze daling is het grootst onder mannelijke en vrouwelijke slachtoffers in de leeftijd van 20 tot en met 39 jaar. Dit onderzoek benadrukt het belang om de discussie rondom de dalende moordtrend te verschuiven naar een verdiepende analyse van geslacht en leeftijd bij slachtoffers.

\section{Inleiding}

Het aandeel moorden ${ }^{1}$ is in een groot aantal westerse landen aan het dalen, minder mensen worden jaarlijks slachtoffer van dodelijk geweld (Aebi \& Linde, 2014; Blumstein e.a., 2000; Eisner, 2008; LaFree e.a., 2015; Lehti, 2014; Trägardh e.a., 2016; Weiss e.a., 2016). Hoewel de meeste trendstudies een daling in moord sinds de jaren negentig observeren, maakt Steven Pinker (2012) in zijn boek The better angels of our nature. Why violence has declined het overtuigende argument dat de daling in dodelijk geweld al sinds de middeleeuwen waarneembaar is. Echter, deze homicide drop is geen universeel verschijnsel. Uitzonderingen betreffen Centraalen Zuid-Amerikaanse regio's, die in de afgelopen decennia juist een stijging in het moordcijfer laten zien, mede gedreven door politieke instabiliteit en drugshandel (Lappi-Seppälä \& Lehti, 2014). Weiss en collega's (2016) concluderen dat de daling het grootst is in landen die al relatief lage moordcijfers laten zien, waaronder de meeste Europese landen, Australië en historisch gezien ook in NoordAmerika. Ook andere studies bevestigen dat de daling sinds de jaren negentig van de vorige eeuw voornamelijk een westers fenomeen is (LaFree e.a., 2015; Tuttle e.a., 2018).

Het doel van dit beschrijvende artikel is het wetenschappelijke debat over de homicide drop te voeden door het slachtofferschap van moord van de afgelopen 25

1 In tegenstelling tot de Engelse taal, kent de Nederlandse taal geen term die moord en doodslag samenvat. In dit artikel zullen we, wanneer we spreken over moord en doodslag, alleen naar moord refereren om de leesbaarheid te vergemakkelijken. 
jaar in Nederland te analyseren. Doordat Nederland ${ }^{2}$ een van de weinige landen is die sinds kort gedetailleerde informatie hebben over de slachtoffers van moorden over een lange periode (1992-2016), vormt het een excellente casus om de langetermijntrend te onderzoeken. We bouwen hierbij voort op het eerder in dit tijdschrift verschenen artikel van Liem en collega's (2012), waarin de moordtrend in Nederland tussen 1992 en 2009 is onderzocht. Het huidige artikel vormt een actualisatie en verdieping van dit werk door de Nederlandse trend in het slachtofferschap van moord in een 25-jarige periode, te weten 1992-2016, nader te onderzoeken, waarbij we controleren voor geslacht en leeftijd.

\section{Methode}

\section{De Dutch Homicide Monitor}

Voor deze studie is gebruik gemaakt van de Dutch Homicide Monitor (DHM), die alle moorden in Nederland in de periode 1992-2016 bijhoudt (Universiteit Leiden, 2019). Deze monitor is een afgeleide van de European Homicide Monitor (EHM): een samenwerking van onderzoekers uit Nederland, Finland en Zweden, die alle moorden van deze landen op een uniforme manier coderen om internationale vergelijkingen mogelijk te maken (zie Granath e.a., 2011; Liem e.a., 2013). ${ }^{3}$ Hoewel we in dit artikel alleen spreken over 'moord', zijn in de DHM alle delicten opgenomen die volgens het Wetboek van Strafrecht (Sr) vallen onder (medeplegen van of medeplichtig zijn aan) moord (art. $289 \mathrm{Sr}$ ) dan wel (gekwalificeerde) doodslag (art. 287-288 Sr). Met andere woorden, dit betreft delicten waarbij een dader een slachtoffer opzettelijk - en in het geval van moord met voorbedachten rade - om het leven heeft gebracht. Er zijn daarom geen pogingen tot moord dan wel doodslag in de monitor opgenomen.

Een gebeurtenis wordt in de DHM opgenomen wanneer deze door de politie wordt geregistreerd als moord dan wel doodslag. Alle slachtoffers en individuen die door de politie worden verdacht van betrokkenheid bij de moord staan in de DHM. ${ }^{4}$ Dit betekent dat niet alle verdachten vervolgd en veroordeeld worden voor moord. Hoewel bij deze keuze enige kanttekeningen te maken zijn, is besloten om het startpunt van een moordzaak - dat de politie in haar systemen regis-

2 Andere landen die ook over dergelijke gedetailleerde informatie over moord en doodslag over een lange periode beschikken, zijn Finland (Lehti, 2014) en Zweden (Trägardh e.a., 2016). Nederland vormt samen met deze landen de European Homicide Monitor, waarbij zaak-, dader- en slachtofferkarakteristieken hetzelfde zijn gecodeerd om internationale vergelijkingen mogelijk te maken (Liem e.a., 2013). Steeds meer landen, waaronder Zwitserland, Italië, Denemarken en Estland, maken deel uit van de European Homicide Monitor, wat een internationale vergelijking vergemakkelijkt.

3 Hoewel de DHM overeenstemming toont met de toenmalige Moord en Doodslag Monitor van Nieuwbeerta en Leistra (2003), is de DHM aan de hand van andere bronnen samengesteld en geeft hij een andere invulling aan variabelen die inzicht geven in zaak-, dader- en slachtofferkarakteristieken over een langere periode.

4 In de DHM hebben we het niet over verdachten, omdat een groot deel van de verdachten uiteindelijk wordt veroordeeld voor moord of doodslag. Om deze reden hebben we gekozen voor de toepasselijkere term 'daders'. 
treert - als uitgangspunt te nemen. Deze keuze komt overeen met de definitie die de gevalideerde dataset EHM (Liem e.a., 2013) en eerder internationaal onderzoek (zie bijv. Bryant \& Cussen, 2015) hanteren. Voor een uitgebreide methodologische verantwoording van de DHM, zie het codeboek van de Universiteit Leiden (2019).

In de DHM zijn alle moorden sinds het jaar 1992 opgenomen. Voorafgaand aan 1992 werden moorden niet uniform geregistreerd. De DHM is gebaseerd op informatie afkomstig uit verschillende, elkaar aanvullende bronnen: (1) alle ANPberichten over moorden in Nederland en het weekblad Elsevier, dat jaarlijks een overzicht van alle moorden gepleegd in Nederland publiceert, samengesteld door misdaadjournalist Gerlof Leistra, (2) informatie uit de Basisvoorziening Handhaving (BVH) van de Nationale Politie, waarin gegevens over het delict, dader(s) en slachtoffer(s) geregistreerd zijn, (3) informatie uit COMPAS/GPS van het Openbaar Ministerie over het strafproces indien vervolging heeft plaatsgevonden, ${ }^{5}$ en tot slot gedetailleerde informatie uit (4) beschikbare strafdossiers bij de tien arrondissementsparketten en (5) Pro Justitia-rapportages. Hierdoor bevat de DHM gedetailleerde informatie over slachtoffer(s) en dader(s) van elke moord, hun achtergrondkarakteristieken en eventuele criminele carrières, alsook informatie over het delict en de juridische vervolging.

Deze bronnen zijn niet alleen een aanvulling op elkaar, maar zijn ook gebruikt ter validatie dat alle moorden die in Nederland hebben plaatsgevonden in de DHM zijn opgenomen. Zo vormen de jaarlijkse moordlijsten van het weekblad Elsevier de basis van de monitor. Deze moorden worden aangevuld met informatie uit ANP-berichten, de BVH, COMPAS van het Openbaar Ministerie en strafdossiers. Daarna is een aanvullende validatie met informatie uit de BVH en data over de tenlasteleggingen van het Openbaar Ministerie gedaan om er zeker van te zijn dat de zaken moordzaken betreffen en niet bijvoorbeeld een fataal ongeluk. Daarnaast zijn er via deze validatie andere moordzaken aan het licht gekomen die volgens de criteria in de DHM moeten worden opgenomen. Via de verschillende bronnen hebben we getracht een zo compleet mogelijk beeld te krijgen van alle moordzaken in Nederland in de periode 1992-2016.

\section{Analyse}

De resultatensectie kent twee delen. In het eerste deel is op zaakniveau een beschrijving gegeven van de omstandigheden waaronder de slachtoffers zijn gedood (zie tabel 1). We beschrijven hoeveel daders en slachtoffers betrokken waren bij de moord. Ook beschrijven we het type moord dat is geclassificeerd aan de hand van de slachtoffer-daderrelatie en het motief van de dader(s) om het slachtoffer te doden. Deze variabele is afkomstig van de EHM, die een gevalideerde coderingslijst heeft (zie Ganpat \& Liem, 2012; Liem e.a., 2013), en is in lijn met eerdere onderzoeken naar moord en doodslag in Nederland (zie bijv. Nieuwbeerta \& Leistra, 2003). ${ }^{6}$ Deze variabelen zijn echter over de periode 1997-2016

5 Informatie van COMPAS/GPS hebben we via RACmin van het WODC gekregen.

6 Een uitgebreide beschrijving van deze variabele inclusief de kanttekeningen die gepaard gaan met deze categorisatie is te vinden in Universiteit Leiden, 2019. 
Tabel 1 Beschrijvende zaakkarakteristieken van alle moorden in Nederland in de periode 1992-2016 $(N=4.845)$

\begin{tabular}{|c|c|c|}
\hline & $\mathbf{N}$ & $\%$ \\
\hline \multicolumn{3}{|l|}{ Aantal slachtoffers-daders* } \\
\hline I slachtoffer \& I dader & 2.152 & 71,4 \\
\hline$>$ I slachtoffer \& I dader & 113 & 3,7 \\
\hline I slachtoffer \& > I dader & 683 & 22,6 \\
\hline$>$ I slachtoffer \& > I dader & 68 & 2,3 \\
\hline Onbekend & 52 & \\
\hline Onopgeloste zaken & 533 & \\
\hline \multicolumn{3}{|l|}{ Type moord* } \\
\hline Doding in gezinsverband & 1.100 & 36,5 \\
\hline Ruziemoorden & 803 & 26,6 \\
\hline Moorden in het criminele milieu & 308 & 10,2 \\
\hline Roofmoorden & 231 & 7,7 \\
\hline Moorden gepleegd door persoon met psychische stoornis & 105 & 3,5 \\
\hline Seksuele moorden & 56 & 1,8 \\
\hline Overig/onbekend & 413 & 13,7 \\
\hline Onopgeloste zaken & 533 & \\
\hline \multicolumn{3}{|l|}{ Locus delicti } \\
\hline Woning & 2.399 & 51,4 \\
\hline Straat, openbare weg, openbaar vervoer & 1.079 & 23,1 \\
\hline Winkel, restaurant, hotel & 330 & 7,1 \\
\hline Park, bos, recreatiegebied & 253 & 5,4 \\
\hline Werkplek & 157 & 3,4 \\
\hline Overig & 446 & 9,6 \\
\hline Onbekend & $|8|$ & \\
\hline \multicolumn{3}{|l|}{ Modus operandi } \\
\hline Vuurwapen & 1.565 & 35,1 \\
\hline Steekwapen & 1.542 & 34,6 \\
\hline Wurging, verstikking & 533 & 12,0 \\
\hline Fysiek geweld & 299 & 6,7 \\
\hline Slagwapen & 263 & 5,9 \\
\hline Overig & 251 & 5,7 \\
\hline Onbekend & 392 & \\
\hline \multicolumn{3}{|l|}{ Geografische spreiding } \\
\hline Stedelijk & 3.617 & 74,9 \\
\hline Niet-stedelijk & 1.212 & 25,1 \\
\hline Onbekend & 16 & \\
\hline
\end{tabular}

NB Onbekende informatie wordt in tabel I gerapporteerd, maar de percentages zijn berekend op wat bekend is.

* Berekend over de periode 1997-2016. 
berekend, omdat de informatie die in de BVH en COMPAS is geregistreerd pas vanaf 1997 betrouwbaar wordt geacht. Vanaf dit jaartal konden we achterhalen of de zaak opgehelderd was, waardoor we het aantal slachtoffers en daders per zaak en het type moord konden bepalen. Voor de definitie van de opheldering van een moordzaak sluiten we aan bij de definitie die Liem en collega's (2018) gebruiken. In hun artikel over opgeloste moordzaken in West-Europa operationaliseren ze een moordzaak als opgehelderd wanneer de politie is overgegaan tot de arrestatie van (een) verdachte(n). Ook 'buitengewone ophelderingen' (exceptionally cleared) vallen hieronder. Dit zijn gevallen waarbij de verdachte niet kan worden gearresteerd omdat hij of zij zelfmoord heeft gepleegd of is gevlucht naar het buitenland. De overige variabelen omtrent de moord, zoals beschreven in tabel 1, zijn wel over de gehele periode beschreven omdat informatie over de plek waar de moord plaatsvond (locus delicti), of er een wapen was gebruikt (modus operandi) en de geografische plaats vaak in de ANP-berichten te achterhalen waren. Bij het onderverdelen van de pleegplaats naar stedelijk/niet-stedelijk is gebruik gemaakt van de definitie van het Centraal Bureau voor de Statistiek (hierna: CBS).

In het tweede deel van de resultatensectie zal de analyse van de moordtrend worden beschreven. Deze is in ratio's (slachtofferschap per 100.000 inwoners) berekend, waarbij gecorrigeerd is voor het inwoneraantal per jaar. De gegevens over het inwoneraantal per jaar zijn afkomstig van CBS StatLine. Daarnaast is er gecorrigeerd voor geslacht en leeftijd. Op basis van de gegevens uit CBS StatLine is het aandeel vrouwen en mannen per jaar in de volgende vier leeftijdscategorieën berekend: jongeren (jonger dan 20 jaar), jongvolwassenen (20-39 jaar), volwassenen (40-64 jaar) en ouderen (65 jaar en ouder). De moordtrend waarbij gecorrigeerd is voor leeftijd en geslacht is ook in ratio's (slachtofferschap per 100.000 inwoners) geanalyseerd.

\section{Resultaten}

\section{5 jaar moord in Nederland}

In totaal hebben er in Nederland tussen 1 januari 1992 en 31 december 2016 4.845 moordzaken plaatsgevonden. Het aantal moordzaken is over 25 jaar gedaald van 247 zaken in 1992 naar 102 zaken in 2016. Het ophelderingspercentage voor moord in Nederland (in de periode 1997-2016), dat wil zeggen wanneer de politie één of meerdere verdachten arresteert, is 84 procent. In de meeste zaken draaide het om één slachtoffer en één dader (71,4 procent), gevolgd door zaken waarbij meerdere daders betrokken waren bij het doden van één slachtoffer (22,6 procent). In de afgelopen 25 jaar vond een op de drie dodingen in gezinsverband plaats (36,5 procent), gevolgd door ruziemoorden (26,6 procent). Moorden in het criminele circuit en roofmoorden waren de derde en vierde grootste groep (10,2 procent respectievelijk 7,7 procent). Moorden gepleegd door individuen met een psychische stoornis en seksuele moorden vormden de kleinste groepen (zie tabel 1). In ongeveer een derde van de zaken werden slachtoffers gedood met een vuurwapen (35,1 procent), gevolgd door een steekwapen (34,6 procent). Wurging (12 procent) en fysiek geweld (6,7 procent) kwamen op de derde en vierde plek. 


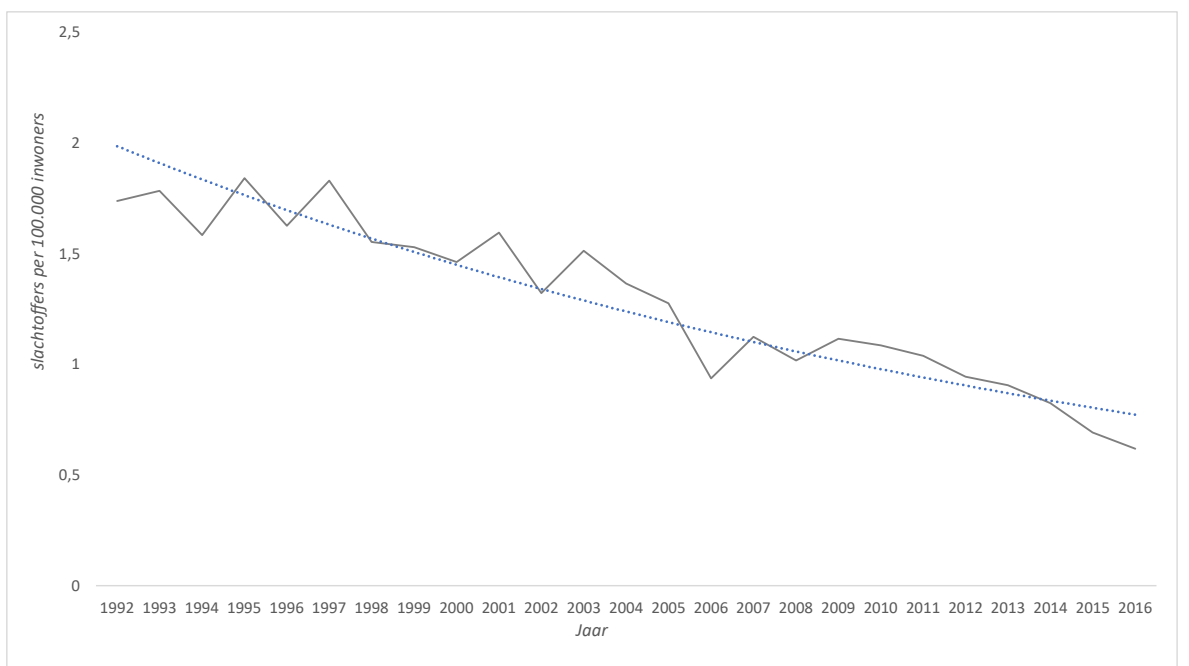

Figuur 1 Slachtofferratio van moord per 100.000 inwoners in Nederland in de periode 1992-2016

Overige modus operandi, de kleinste categorie (5,7 procent), omvatten onder andere het gebruik van gif, vuur, een bom of een voertuig om het slachtoffer te doden. Iets meer dan de helft van de levensdelicten vond plaats achter gesloten deuren (51,4 procent). Daarnaast vond de moord plaats op openbare plekken, waaronder wegen of openbaar vervoer (23,1 procent), winkels, restaurants, cafés, hotels ( 7,1 procent) of een bos, park en recreatiegebied (5,4 procent). De meeste moorden werden in stedelijke gebieden gepleegd ( 74,9 procent).

Bij al deze levensdelicten zijn in totaal 5.170 slachtoffers om het leven gebracht. Er is over de algehele periode een daling in slachtoffers van moord waar te nemen (zie figuur 1). In het begin van de jaren negentig vielen aanzienlijk meer slachtoffers (zowel in absolute aantallen als in ratio) dan aan het einde van die periode. In 1995 en 1997 telden we de hoogste slachtofferratio per 100.000 inwoners. Vanaf 2003 zien we een sterke dalende trend van 1,51 slachtoffers per 100.000 inwoners naar 0,94 slachtoffers per 100.000 inwoners in 2006. Hoewel er een kleine stijging waar te nemen is in 2007, blijft de dalende trend zich voortzetten naar 0,62 slachtoffers per 100.000 inwoners in 2016. In de eerste periode van deze 25-jarige trendanalyse (1992-2003) is de slachtofferratio rond de 1,62 slachtoffers per 100.000 inwoners. In de tweede periode (2004-2016) is deze ratio gedaald naar gemiddeld 1,00 slachtoffer van dodelijk geweld per 100.000 inwoners.

\section{Geslacht en leeftijd}

Een opsplitsing naar geslacht en leeftijd laat het volgende zien. De meeste slachtoffers van moord waren mannen (68,8 procent). Er is geen significant leeftijds- 


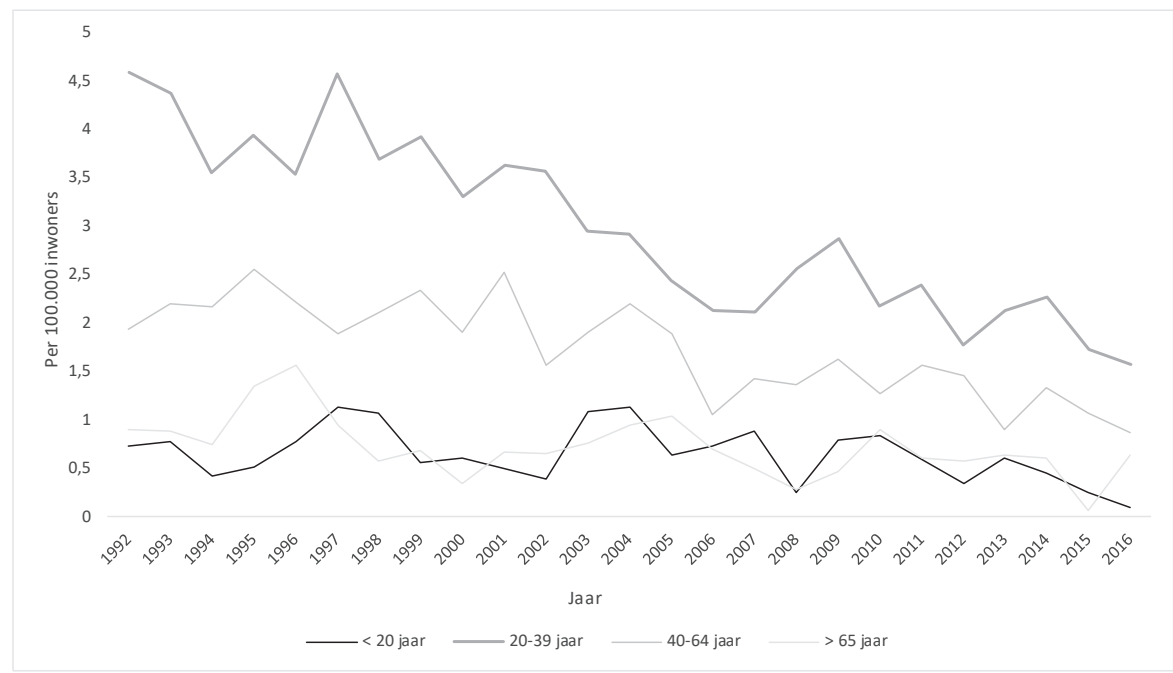

Figuur 2a Ratio mannelijke slachtoffers van moord, opgesplitst in leeftijdscategorieën, per 100.000 inwoners in Nederland in de periode 1992-2016

verschil tussen de mannelijke en vrouwelijke slachtoffers waar te nemen ( $t$ $(4948)=-0,73, p=0,47)$. De gemiddelde leeftijd van de mannelijke slachtoffers was 36,58 jaar ( $M d n=35$ jaar, $S D=15,72)$ en van de vrouwelijke slachtoffers 36,97 jaar $(\mathrm{Mdn}=35$ jaar, $S D=20,17)$. Figuur 2 a toont de ratio mannelijke slachtoffers per 100.000 inwoners van de afgelopen 25 jaar opgedeeld in de leeftijdscategorieën jongeren (jonger dan 20 jaar), jongvolwassenen (20-39 jaar), volwassenen (40-64 jaar) en ouderen (65 jaar en ouder). De grootste daling is te vinden onder de mannen in de leeftijd 20-39 jaar. De slachtofferratio van deze groep is van 4,58 per 100.000 inwoners in 1992 gezakt naar 1,57 slachtoffers per 100.000 inwoners in 2016. Ook de daling in deze groep is het sterkst gecorreleerd met de algemene moordtrend $\left(r_{s}=0,92, p<0,00\right)$. De daling onder volwassen mannen in de leeftijd 40-64 jaar hangt eveneens sterk samen met de algemene moordtrend $\left(r_{s}=0,88\right.$, $p<0,00)$. In 1992 vielen er nog 1,93 mannelijke slachtoffers per 100.000 inwoners in de leeftijd 40-64 jaar. Hoewel deze ratio in de beginjaren nog schommelde, met enkele pieken in 1995, 1999, 2001 en 2004, is de ratio vanaf 2005 gaan dalen. In 2016 vielen er 0,88 mannelijke slachtoffers per 100.000 inwoners. De dalende trend onder de mannelijke slachtoffers in de twee overige leeftijdscategorieën jongeren en ouderen - hangen significant, maar minder sterk samen met de algemene trend (voor jongvolwassenen: $r_{s}=0,43, p=0,003$; voor ouderen: $r_{s}=0,60$, $p=0,002)$. Figuur 2a laat de dalingen van de vier leeftijdscategorieën zien.

Ook bij de vrouwelijke slachtoffers is de daling het grootst onder de jongvolwassenen $\left(r_{s}=0,88, p<0,000\right)$. Tot aan 2003 bleef de ratio vrouwelijke slachtoffers rond de 1,56 slachtoffers per 100.000 inwoners. Daarna is er een sterke daling naar 


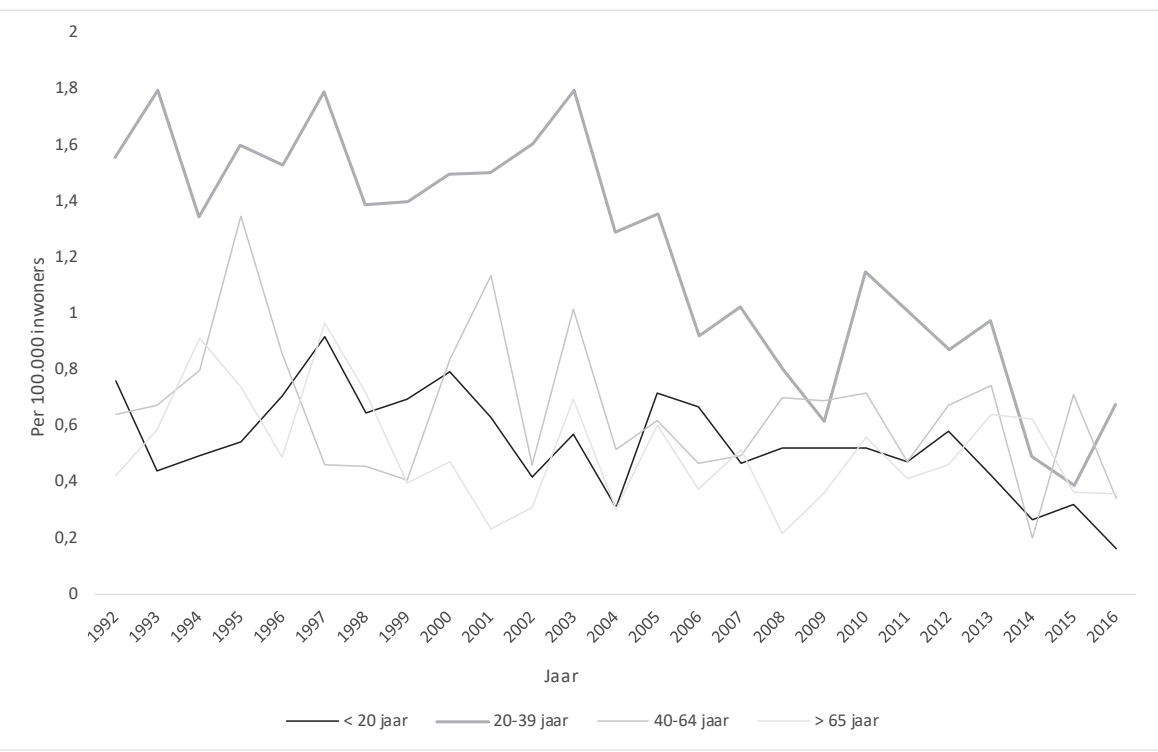

Figuur 2b Ratio vrouwelijke slachtoffers van moord, opgesplitst in leeftijdscategorieën, per 100.000 inwoners in Nederland in de periode 1992-2016

0,68 vrouwelijke slachtoffers per 100.000 inwoners in 2016. Ook onder de jonge vrouwen tot 20 jaar is de daling gecorreleerd aan de algemene moordtrend $\left(r_{s}=0,55, p=0,005\right)$. De slachtofferratio is van 0,76 per 100.000 inwoners in 1992 gezakt naar 0,16 in 2016. De daling in de overige twee leeftijdscategorieën, volwassenen in de leeftijd 40-64 jaar en ouderen van 65 jaar en ouder, correleren niet met de algemene trend. Met andere woorden, de hoeveelheid vrouwelijke slachtoffers in de leeftijdsgroepen 40-64 jaar en 65 jaar en ouder biedt geen verklaring voor de daling in de algemene moordtrend.

\section{Discussie}

Het doel van dit artikel is een actualisatie en nadere bestudering van de Nederlandse moordtrend. Hierbij hebben we een - in de (inter)nationale literatuur unieke - periode van 25 jaar (1992-2016) gehanteerd. Tot op heden is dergelijk onderzoek, gedurende een lange observatieperiode, nog niet gedaan in Nederland. Hoewel eerder onderzoek naar de Nederlandse moordtrend een daling in de periode 1992-2009 heeft geconstateerd (zie Ganpat \& Liem, 2012; Liem e.a., 2012), blijkt uit onze analyse dat de daling in de moordtrend in Nederland stevig doorzet na 2009. In 2009 vielen er 1,12 slachtoffers per 100.000 inwoners. Deze ratio is sindsdien gezakt en in 2016 was de ratio 0,62 slachtoffers per 100.000 inwoners. Deze daling in Nederland is vergelijkbaar met andere westerse landen die een daling in het moordcijfer laten zien, waaronder Finland en Zweden (Lehti, 
2014; Trägardh e.a., 2016). Volgens het UNODC (2018) heeft Nederland wereldwijd een van de laagste moordcijfers, en is daarmee vergelijkbaar met Zwitserland, Tsjechië en Spanje. Het is echter de vraag of deze daling in het moordcijfer zich nog verder doorzet, of dat de bodem is bereikt.

De grootste daling is waar te nemen onder de mannelijke slachtoffers in de leeftijd 20-64 jaar. Een van de hypothesen om deze specifieke daling te kunnen verklaren is gelegen in de gelegenheidstheorie en de daaruit voortvloeiende levensstijltheorie. Eerdere studies door onder anderen Aebi en Linde (2014) beargumenteren dat het voornamelijk een veranderde of aangepaste levensstijl is die ervoor zorgt dat mannen rond de leeftijd van 30-40 jaar hun vrije tijd vaker binnenshuis en in gesuperviseerde ruimtes doorbrengen. Daarbij lopen ze minder risico om dader dan wel slachtoffer te worden van moord. De komst en de wijdverspreide rol van het internet zou van grote invloed kunnen zijn op de ontwikkeling van deze aangepaste levensstijl (Aebi \& Linde, 2014). Maar ook onder de jongvolwassen vrouwelijke slachtoffers is er een sterke daling gevonden. Niet alleen een veranderde levensstijl zou deze daling kunnen verklaren, maar ook de toegang tot professionele hulp wordt als reden geopperd voor de daling in het moordcijfer onder jongvolwassen vrouwen. Vrouwen in deze leeftijd zijn voornamelijk slachtoffers van fataal huiselijk geweld (UNODC, 2018; Stöckl e.a., 2013) en de vergrote toegankelijkheid van professionele hulp kan voorkomen dat huiselijk geweld hun fataal wordt.

\section{Beperkingen}

Hoewel de Dutch Homicide Monitor op (inter)nationaal niveau een van de weinige monitoren is die gedetailleerde informatie bevat over zaak-, dader- en slachtofferkarakteristieken van alle levensdelicten die hebben plaatsgevonden in Nederland sinds 1992, zijn er drie kanttekeningen c.q. voorzichtigheden te plaatsen bij deze monitor. Ten eerste is de DHM afhankelijk van secundaire bronnen, die voornamelijk in de jaren negentig geen goede registratiesystemen kenden. Zo beschikken we over weinig informatie over de daders en slachtoffers van moord of doodslag in de periode 1992-1996. Ook is de documentatie hedendaags beter dan in de eerdere jaren; dit geldt vooral voor digitale documentatie. Ten tweede worden alle verdachten van moord of doodslag in de DHM opgenomen, ook wanneer zij uiteindelijk niet veroordeeld worden voor moord of doodslag. Dit kan van invloed zijn wanneer trends op slachtofferschap- (en uiteraard op daderschap)niveau worden bestudeerd, omdat de omvang van de slachtofferpopulatie groter is dan wanneer strikt genomen alleen zaken met een veroordeling voor moord of doodslag het uitgangspunt vormen. Hoewel een dergelijke, relatief brede, opzet nader onderzoek mogelijk maakt op het niveau van zowel verdachten als vervolgden en veroordeelden van moord, moeten de bevindingen in deze onderzoeksnotitie daarom met inachtneming van de selectiecriteria worden geïnterpreteerd. Een laatste kanttekening betreft het dark number van moorden. Het is niet uit te sluiten dat zelfs bij moorden sprake is van een dark number, onder andere door langdurige vermissingen en de misclassificatie van onnatuurlijke doodsoorzaken als suïcide of een ongeluk (Neuilly, 2011; Timmermans, 2007). Het is echter moeilijk te achterhalen hoe hoog dit aantal is, omdat het afhankelijk 
is van organisatorische en medische procedures die een rol spelen bij het bepalen van de doodsoorzaak (Neuilly, 2011).

\section{Conclusie}

Dit onderzoek is de eerste studie die over een periode van 25 jaar een verdiepende analyse doet naar de moordtrend in Nederland. We zien een dalende trend in moord in Nederland en dat deze daling het sterkst is onder mannen en vrouwen in de leeftijd 20-39 jaar. Onze bevindingen benadrukken het belang dat de demografische kenmerken het startpunt zijn en een (beginnende) verklaring kunnen bieden voor de dalende moordtrend. In toekomstig onderzoek zou de relatie tussen geslacht, leeftijd en type moord verder kunnen worden onderzocht, iets dat tot op heden nauwelijks is gedaan. Moord kent namelijk vele verschijningsvormen, die elk onderhevig zijn aan verschillende onderliggende kenmerken, waaronder geslacht en leeftijd. Om een adequate beschrijving en duiding te geven van de moordtrend, dient men rekening te houden met de complexiteit en heterogeniteit van moord. We pleiten daarom voor een verschuiving in theoretische benadering naar de mannelijke en vrouwelijke jongvolwassenen om de dalende trend verder te ontrafelen en zodoende meer inzicht te geven in mogelijke typegebaseerde preventiestrategieën. Dergelijk vervolgonderzoek zou ons nadere handvatten kunnen geven om de daling in het moordcijfer, die thans gaande is, te behouden.

\section{Literatuur}

Aebi, M. \& Linde, A. (2014). The persistence of lifestyles. Rates and correlates of homicide in Western Europe from 1960 to 2010. European Journal of Criminology, 11(5), 552-577.

Blumstein, A., Rivara, F.P. \& Rosenfeld, R. (2000). The rise and decline of homicide - and why. Annual Review of Public Health, 21, 505-541.

Bryant, W. \& Cussen, T. (2015). Homicide in Australia: 2010-11 to 2011-12. National Homicide Monitoring Program report. Canberra: Australian Institute of Criminology.

Eisner, M. (2008). Modernity strikes back? A historical perspective on the latest increase in interpersonal violence, 1960-1990. International Journal of Conflict and Violence, 2(2), 288-316.

Ganpat, S.M. \& Liem, M. (2012). Homicide in the Netherlands. In: M. Liem \& W.A. Pridemore (eds.). Handbook of European homicide research: patterns, explanations and country studies. New York: Springer, 329-241.

Granath, S., Hagstedt, J., Kivivuori, J., Lehti, M., Ganpat, S.M., Liem, M. \& Nieuwbeerta, P. (2011). Homicide in Finland, the Netherlands and Sweden. A first study on the European Homicide Monitor Data. Stockholm: Swedisch Council for Crime Prevention.

LaFree, G., Curtis, K. \& McDowall, D. (2015). How effective are our 'better angels'? Assessing country-level declines in homicide since 1950. European Journal of Criminology, 12(4), 482-504.

Lappi-Seppälä, T. \& Lehti, M. (2014). Cross-comparative perspectives on global homicide trends. Crime and Justice, 43(1), 135-230. 
Lehti, M. (2014). Homicide drop in Finland, 1996-2012. Journal of Scandinavian Studies in Criminology and Crime Prevention, 15(2), 182-199.

Liem, M., Wilsem, J. van, Smit, P. \& Nieuwbeerta, P. (2012). De daling van moord en doodslag in Nederland. Tijdschrift voor Criminologie, 54(1), 18-32.

Liem, M., Suonpää, K., Lehti, M., Kivivuori, J., Granath, S., Walser, S. \& Killias, M. (2018). Homicide clearance in Western Europe. European Journal of Criminology. doi: 10.1177/1477370818764840.

Liem, M., Ganpat, S.M., Granath, S., Hagstedt, J., Kivivuori, J., Lehti, M. \& Nieuwbeerta, P. (2013). Homicide in Finland, the Netherlands, and Sweden. First findings from the European Homicide Monitor. Homicide Studies, 17(1), 75-95.

Neuilly, M-A. (2011). Impact of medico-legal practices on mortality statistics and their use in comparative research. Victims \& Offenders: An International Journal of Evidence-based Research, Policy, and Practice, 6(3), 306-320.

Nieuwbeerta, P. \& Leistra, G. (2003). Moord en doodslag in Nederland. Een overzicht van alle zaken in de periode 1992-2001. Tijdschrift voor Veiligheid een Veiligheidszorg, 3(2), 36-54.

Pinker, S. (2012). The better angels of our nature. Why violence has declined. New York: Penguin Group.

Stöckl, H., Devries, K., Rotstein, A., Abrahams, N., Campbell, J., Watts, C. \& Moreno, C.G. (2013). The global prevalence of intimate partner homicide. A systematic review. The Lancet, 382, 859-865.

Timmermans, S. (2007). Postmortem. How medical examiners explain suspicious deaths. Chicago: The University of Chicago Press.

Trägardh, K., Nilsson, T., Granath, S. \& Sturup, J. (2016). A time trend study of Swedish male and female homicide offenders from 1990 to 2010. International Journal of Forensic Mental Health, 15(2), 125-135.

Tuttle, J., McCall, P.L. \& Land, K.C. (2018). Latent trajectories of cross-national homicide trends. Structural characteristics of underlying groups. Homicide Studies. doi: 10.11771/1088767918774083.

Universiteit Leiden (2019). Dutch Homicide Monitor, coding book. Gevonden op www.europeanhomicide.com.

UNODC (2018). Gender-related killing of women and girls. Vienna: UNDOC.

Weiss, D.B., Santos, M.R., Testa, A. \& Kumar, S. (2016). The 1990s homicide decline: a Western world or international phenomenon? A research note. Homicide Studies, 20(4), 321-334. 